
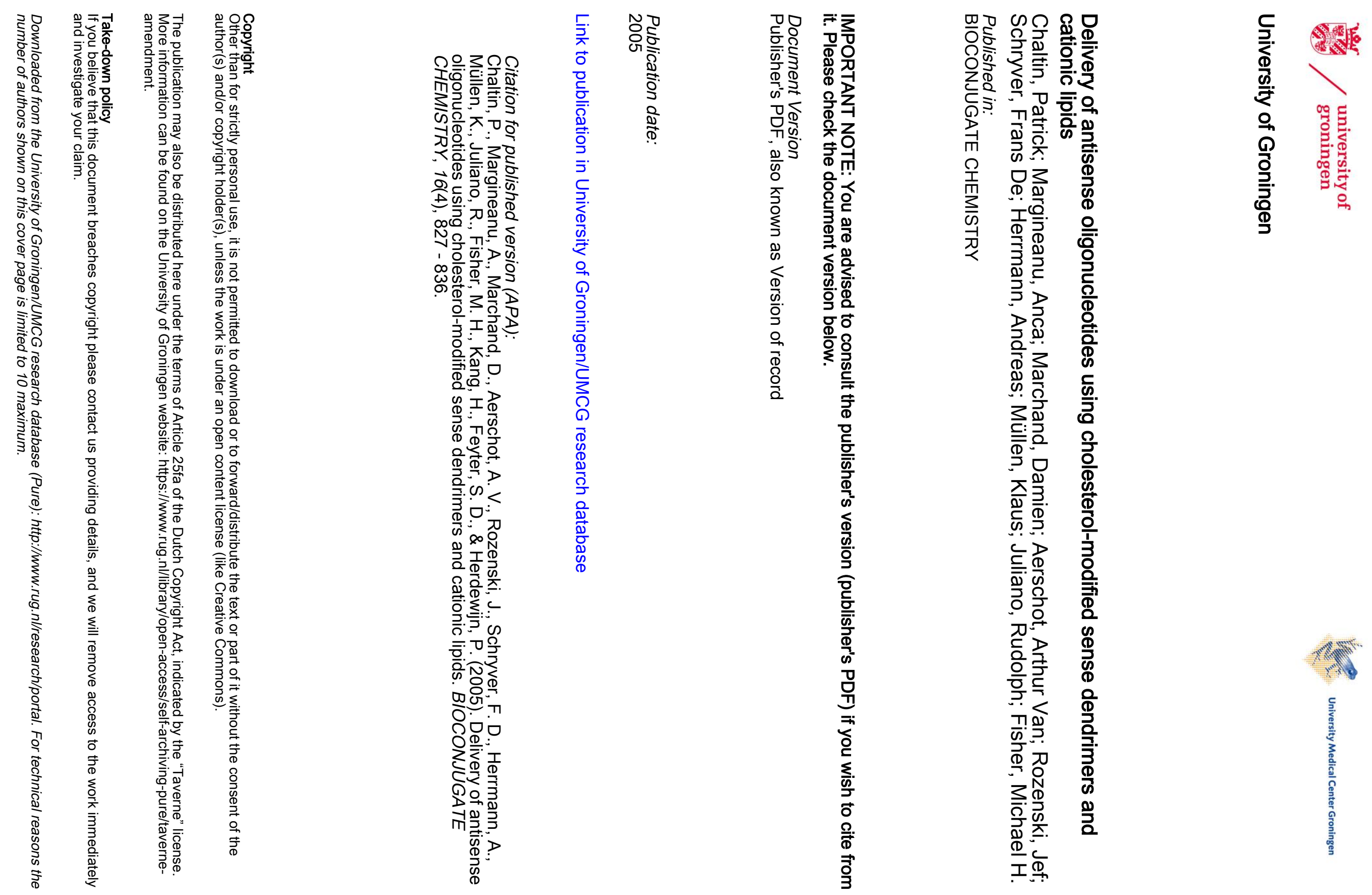


\title{
Delivery of Antisense Oligonucleotides Using Cholesterol-Modified Sense Dendrimers and Cationic Lipids
}

\author{
Patrick Chaltin, ${ }^{\dagger}$ Anca Margineanu, ${ }^{\ddagger}$ Damien Marchand,${ }^{\dagger}$ Arthur Van Aerschot,${ }^{\dagger}$ Jef Rozenski, ${ }^{\dagger}$ \\ Frans De Schryver, Andreas Herrmann," Klaus Müllen," Rudolph Juliano, ${ }^{\S}$ Michael H. Fisher, ${ }^{\S}$ \\ Hyunmin Kang, ${ }^{\S}$ Steven De Feyter, ${ }^{\ddagger}$ and Piet Herdewijn ${ }^{\dagger} * *$
}

Laboratory for Medicinal Chemistry, Rega Institute, Catholic University of Leuven, Minderbroedersstraat 10 , B-3000 Leuven, Belgium, Laboratory of Photochemistry and Spectroscopy, Catholic University of Leuven, Celestijnenlaan 200F, B-3000 Leuven, Belgium, Department of Pharmacology, University of North Carolina School of Medicine, 1106 Mary Ellen Jones Building Campus Box 7365, Chapel Hill, North Carolina 27599-7365, and Max-Planck-Institut für Polymerforschung, Ackermannweg 10, D-55021 Mainz, Germany. Received January 28, 2005; Revised Manuscript Received April 15, 2005

Cholesterol modified mono-, di-, and tetrameric oligonucleotides were synthesized and hybridized with antisense oligonucleotides to study their incorporation in cationic liposomes together with the influence of this dendrimeric delivery system on biological activity. Electrostatic interactions seem to play the most important role during complexation with cationic lipids. This oligonucleotide formulation gives a small but significant increase in the inhibition of P-glycoprotein expression in a cellular system.

\section{INTRODUCTION}

Antisense oligonucleotides are very powerful tools for inhibition of gene expression (1). The initial hurdles of enzymatic instability and poor hybridization strength of natural antisense oligonucleotides have been largely overcome by introducing chemical modifications. Delivery of oligonucleotides to target cells in vivo, however, is the major bottleneck for the widespread use of antisense oligonucleotides in therapy (2).

One of the potential solutions for this delivery problem is the use of liposomes (3). The antisense oligonucleotide (negatively charged due to the ionization of the phosphate backbone) interacts electrostatically with the cationic phospholipids forming the vesicles and is delivered to the cell by endocytosis. However, the number of oligonucleotides trapped into one complex is low. The delivery process can be improved by conjugation of the antisense oligonucleotide with cholesterol (4) or by the use of cholesterol for liposome formulations (5). A disadvantage of the first approach is that the cholesterol moiety is covalently attached to the oligonucleotide which influences the intracellular distribution of the antisense oligonucleotide.

Despite the efforts that have been made to characterize the formation of DNA-cationic liposome complexes (lipoplexes), the process is not yet completely understood. This is because multiple factors can influence their formation, such as the ratio between the number of negative charges in DNA and that of the positive charges in liposomes,

* To whom correspondence should be addressed. Fax: +32 16 337341. Tel.: +32 16 337387. Piet.Herdewijn@ rega.kuleuven.ac.be.

Laboratory for Medicinal Chemistry, Rega Institute, Catholic University of Leuven.

$\$$ Laboratory of Photochemistry and Spectroscopy, Catholic University of Leuven.

$\S$ University of North Carolina School of Medicine.

" Max-Planck-Institut für Polymerforschung. the fluidity of the lipid bilayer, and the formation of lipid domains after DNA binding (6). Furthermore, the size instability was correlated with high transfection efficiency in vivo (7). The current view about the organization of lipoplexes comes from electron microscopy and X-ray diffraction studies $(8,9)$. According to these, lipoplexes have a multilamellar structure with repeat distances equivalent to the thickness of a lipid bilayer and a single DNA double helix.

Here we investigated the approach of derivatization of an enzymatic labile sense-DNA with cholesterol and delivering the enzymatic stable antisense oligonucleotide as hybrid with this cholesterol-sense-DNA. As well as monomers, dimers and tetramers of sense-DNA were synthesized (Figure 1). Cationic lipids are used for the liposome formulation. This approach has the advantage that the enzymatic stable antisense oligonucleotide itself is not derivatized (i.e. its intracellular distribution and hybridization with its target is not influenced by a reporter group). The cholesterol-modified sense-DNA may stay locked in the endosomes and may be slowly degraded while the enzymatically more stable antisense oligonucleotide can diffuse into the cytoplasm and/or the nucleus (10). The synthesis was tested using an 11-mer as well as an 18-mer sense-DNA. For biological activity determination, we selected the 18-mer, as this length seems to be optimal for this purpose (10). The antisense oligonucleotide that is used as a model is a phosphorothioate 20 gapmer consisting of $2^{\prime}$-methyloxyethyl ( $2^{\prime}$ MOE) nucleotides in the flanks and phosphorothioate DNA in the middle (5'-CCAUCCcgacctcgCGCUCC- $\left.3{ }^{\prime}\right)$. The phosphorothioate DNA gap of eight nucleotides allows RNaseH to play a role in the mode of action of the antisense oligonucleotide. The phosphorothioate $2^{\prime}$ MOE flanks render the oligonucleotide stable against enzymatic degradation. This sequence has been demonstrated to inhibit P-glycoprotein expression in a cellular system (11). 

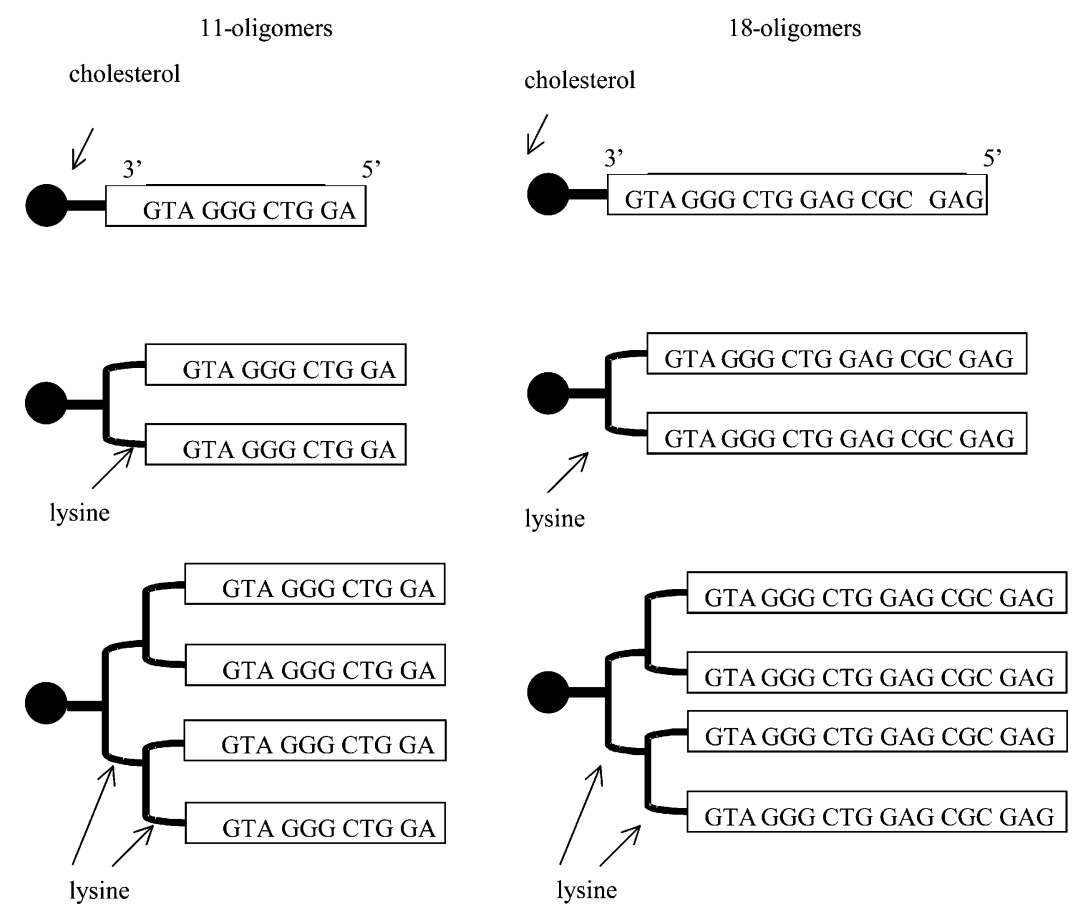

Figure 1. Schematic representation of monomeric and dendrimeric oligonucleotides (DNA) that were used to concentrate antisense oligonucleotides in cationic lipids for cellular delivery (as well, 11-mer as 18-mer oligonucleotides were evaluated as complexing agents for the antisense oligonucleotides).

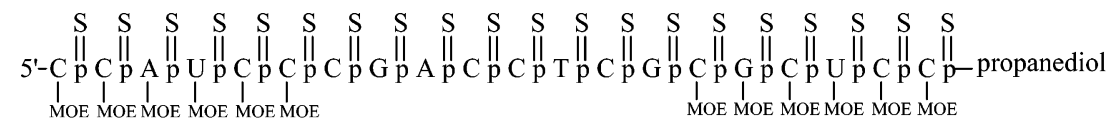

Figure 2. Structure of antisense oligonucleotide directed at mRNA that codes for the P-glycoprotein.

\section{EXPERIMENTAL PROCEDURES}

Chemistry. ${ }^{1} \mathrm{H}$ and ${ }^{13} \mathrm{C}$ NMR spectra were recorded at $200 \mathrm{MHz}$ with a Varian Gemini 200 in $\mathrm{CDCl}_{3} .{ }^{13} \mathrm{C}$ assignments were based on the usual shift increments and calculus values and where necessary confirmed by APT experiments. Assignments of quaternary carbons of the aromatic rings were based on comparison with other compounds and were mostly tentative. Electron impact mass spectra in positive (EI+) and negative ion mode (EI-) were acquired on a Kratos MS50TC mass spectrometer (Kratos, Manchester, UK), using MASPEC II data acquisition software (Mass Spectrometry Services Ltd., Manchester, UK). Electrospray ionization mass spectra in negative ion mode (ESI-) were recorded on a quadruple orthogonal acceleration/time-of-flight mass spectrometer (Q-TOf-2, Micromass, Manchester, UK). Absorption spectra were recorded with a Perkin-Elmer Lambda 40 spectrophotometer (Wellesley, MA) and fluorescence spectra with a Spex Fluorolog 3-22 fluorimeter (Jobin Yvon-Spex Instruments S. A., Inc., Edison, NJ). Precoated Machery-Nagel Alugram SilG/UV 254 plates were used for TLC, and spots were examined with UV light and a sulfuric acid/anisaldehyde spray. Column chromatography was performed on Acros silica gel (60$200 \mathrm{~nm}$ ). Anhydrous solvents were obtained as follows: THF was refluxed on $\mathrm{LiAlH}_{4}$ overnight and was distilled; dichloromethane (DCM) was stored on calcium hydride, refluxed, and distilled; pyridine, triethylamine (TEA), and $N, N$-diisopropylethylamine (DIEA) were refluxed overnight on potassium hydroxide and distilled. $N, N$ Dimethylformamide (DMF) was stored on activated molecular sieves ( $4 \AA$ ) for 3 days and was tested for absence of dimethylamine by the bromophenol test prior to use. DCM, DMF, acetic anhydride $\left(\mathrm{Ac}_{2} \mathrm{O}\right)$, and pyridine were obtained from BDH (Poole, England). Piperidine, trifluoroacetic acid (TFA), diisopropylcarbodiimide (DIC), 1-hydroxybenzotriazole (HOBt), 1-methylimidazole (NMI), ditert-butyl dicarbonate $\left[(\mathrm{Boc})_{2} \mathrm{O}\right]$, benzyl chloroformate, 9-fluorenylmethyloxycarbonyl chloride (FmocCl), 1,8diazabicyclo[5.4.0] undec-7-ene (DBU), and $N$-methylmorpholine were supplied by ACROS (Geel, Belgium). 1-Hydroxy-7-azabenzotriazole (HOAt) and its tetramethyluronium derivative (HATU) were purchased from Perspective Biosystems. [2-(1H-bentotriazole-1-yl)-1,1,3,3tetramethyluronium hexafluorophosphate] (HBTU) from Advanced Chemtech. Benzotriazol-1-yloxytrispyrrolidinophosphonium hexafluorophosphate (PyBOP) was obtained from Advanced Chemtech. Diethyl azodicarboxylate $(\mathrm{DEAD})$ and sodium hydride $(\mathrm{NaH})$ were purchased from Sigma-Aldrich. $p$-[( $R, S)-\alpha-[1-(9 H$-fluoren-9-yl)methoxyformamido]-2,4-dimethoxybenzyl]phenoxyacetic acid (Fmoc-Rink linker) was supplied by Novabiochem. Lipofectamine 2000 was obtained from Invitrogen. PBS buffer (pH7.4) was obtained from Sigma. Oligonucleotide assembly was performed on an Expedite DNA synthesizer (Applied Biosystems) using phosphoramidites from Glen Research.

The 11 and the 18 oligonucleotide sense sequences without cholesterol, as well as the tetramethyl rhodamine (TMR)-labeled oligonucleotide antisense sequence, complementary to the gene encoding the P-glycoprotein (11), were obtained from Invitrogen. The phosphorothioate oligonucleotide from Figure 2 is a gift from ISIS.

Cholesterylacetaldehyde Diethylacetal (2). To a solution of cholesterol ( $5 \mathrm{~g}, 12.9 \mathrm{mmol}, 1$ equiv) in a mixture of anhydrous THF/DMF (1:1, $200 \mathrm{~mL})$ were added $\mathrm{NaH}$ (3.2 g, $77.6 \mathrm{mmol}, 6$ equiv) and, after $5 \mathrm{~min}$, bromoacetaldehyde diethylacetal $(6.3 \mathrm{~mL}, 38.8 \mathrm{mmol}, 3$ 
equiv) under anhydrous conditions. A nitrogen-flushed reflux condensor was attached, and the mixture was heated at reflux for $18 \mathrm{~h}$. The excess $\mathrm{NaH}$ was decomposed using $\mathrm{MeOH} / \mathrm{CH}_{2} \mathrm{Cl}_{2}$ and mild shaking After evaporation to dryness, silica gel-based chromatographic purification was performed with a stepwise gradient of a hexane/EtOAc mixture (98:2 to 95:5) as eluent, yielding $4.3 \mathrm{~g}(8.56 \mathrm{mmol}, 66.3 \%)$ of the title compound. ${ }^{13} \mathrm{C}$ NMR: $\delta=140.97(\mathrm{C}-3), 121.58(\mathrm{C}-4), 101.46(\beta-\mathrm{CH})$, 79.73 (C-1), $68.77\left(\alpha-\mathrm{CH}_{2}\right), 62.09\left(\mathrm{Et}, \mathrm{CH}_{2} \mathrm{O}\right), 56.72(\mathrm{C}-$ 7), 56.12 (C-10), 50.11 (C-14), 42.25 (C-11), 39.73; 39.45; 38.97 (C-2; C-12; C-24), 37.15 (C-16), 36.78 (C-15), 36.12 (C-22), 35.72 (C-20), 31.84 (C-5, C-6), 28.26; 28.13; 27.92 (C-17; C-9; C-25), 24.19; 23.73 (C-8; C-23), 22.73; 22.46 (C-26; C-27), 20.97 (C-13), 19.27 (C-18), 18.60 (C-21), $15.27\left(\mathrm{Et}, \mathrm{CH}_{3}\right), 11.75(\mathrm{C}-19)$. Mass calcd for $[\mathrm{M}+\mathrm{Cl}]^{-}$ $\mathrm{C}_{33} \mathrm{H}_{58} \mathrm{O}_{3} \mathrm{Cl}_{1}$ : 537.4074, found: (ESI-): 537.4094 .

Cholesterylacetaldehyde (3). To a solution of 2 (4.1 g, $8.17 \mathrm{mmol})$ in $\mathrm{CH}_{2} \mathrm{Cl}_{2}(80 \mathrm{~mL})$ was added $20 \mathrm{~mL}$ of TFA $/ \mathrm{H}_{2} \mathrm{O}$ (1:1), and the reaction mixture was stirred for $4.5 \mathrm{~h}$ at room temperature (complete conversion). $\mathrm{NaOH}$ $(1 \mathrm{~N})$ was used to neutralize the solution, and subsequently an extraction with $\mathrm{CH}_{2} \mathrm{Cl}_{2}$ was performed. The organic layer was dried over anhydrous $\mathrm{MgSO}_{4}$, filtered, and evaporated in vacuo to dryness, yielding $3.45 \mathrm{~g}$ (8.07 mmol, 98\%) of the title compound. ${ }^{13} \mathrm{C}$ NMR: $\delta=201.70$ ( $\beta$-CH), 140.30 (C-3), $122.22(\mathrm{C}-4), 80.37(\mathrm{C}-1), 73.81(\alpha-$ $\left.\mathrm{CH}_{2}\right), 56.69$ (C-7), $56.12(\mathrm{C}-10), 50.08$ (C-14), 42.25 (C11), 39.70; 39.42; 38.76 (C-2; C-12; C-24), 36.97 (C-16), 36.72 (C-15), 36.12 (C-22), 35.69 (C-20), 31.81 (C-5, C-6), 28.10; 27.92 (C-17; C-9; C-25), 24.19; 23.73 (C-8; C-23), 22.70; 22.46 (C-26; C-27), 20.97 (C-13), 19.24 (C-18), 18.60 (C-21), 11.75 (C-19). Mass calcd for $[\mathrm{M}]^{+} \mathrm{C}_{29} \mathrm{H}_{48} \mathrm{O}_{2}$ : 428.3654, found (EI+): 428.3647.

Cholesterylacetic Acid (4). Compound 3 (3 g, 7.0 $\mathrm{mmol}$ ) was dissolved in acetone $(105 \mathrm{~mL})$, and $1.5 \mathrm{~mL}$ Jones reagent $\left(26.72 \mathrm{~g} \mathrm{CrO}_{3} / 23 \mathrm{~mL}\right.$ concentrated $\mathrm{H}_{2} \mathrm{SO}_{4} /$ $\mathrm{H}_{2} \mathrm{O}$ to $100 \mathrm{~mL}$ ) was added dropwise while the reaction mixture was cooled on ice. If necessary (TLC), more Jones reagent was added to completely convert $\mathbf{3}$ into its carboxylic acid. After $10 \mathrm{~min}$, acetone and $\mathrm{MeOH}$ were added, the mixture was filtered, and the remaining filtrate was evaporated to dryness. The residual solid was purified by column chromatography on silica gel by elution with hexane/EtOAc/AcOH (8:2:0.1), yielding 2.1 g (4.76 mmol; $68 \%)$ of the title compound. ${ }^{13} \mathrm{C}$ NMR: $\delta=$ $173.54(\mathrm{COOH}), 140.00$ (C-3), 122.46 (C-4), 80.46 (C-1), $65.16\left(\alpha-\mathrm{CH}_{2}\right), 56.69(\mathrm{C}-7), 56.12(\mathrm{C}-10), 50.05(\mathrm{C}-14)$, 42.25 (C-11), 39.67; 39.45; 38.61 (C-2; C-12; C-24), 36.90 (C-16), 36.69 (C-15), 36.12 (C-22), 35.69 (C-20), 31.78 (C5, C-6), 28.13; 28.01; 27.92 (C-17; C-9; C-25), 24.19; 23.73 (C-8; C-23), 22.73; 22.46 (C-26; C-27), 20.97 (C-13), 19.24 (C-18), 18.60 (C-21), 11.75 (C-19). Mass calcd for $[\mathrm{M}]^{+}$ $\mathrm{C}_{29} \mathrm{H}_{48} \mathrm{O}_{3}$ : 444.3603, found (EI-): 444.3606.

No-Fmoc-N $\epsilon$-cholesterylacetyl-lysine-O-Me (5). Compound 4 (1.7 g, $3.7 \mathrm{mmol}, 1$ equiv) and HATU (1.35 $\mathrm{g}, 4.07 \mathrm{mmol}, 1.1$ equiv) were suspended in $85 \mathrm{~mL}$ of dry DMF. To this suspension was added DIEA (1.3 mL, 7.4 mmol, 2 equiv), and the resulting solution was stirred for $2 \mathrm{~h}$ at room temperature. To this mixture was added a solution of Fmoc-Lysine-OMe.HCl $(1.7 \mathrm{~g}, 4.07 \mathrm{mmol}$, 1.1 equiv) and DIEA (1.3 mL, $7.4 \mathrm{mmol}, 2$ equiv) in 15 $\mathrm{mL}$ of dry DMF, and stirring was continued at room temperature for $18 \mathrm{~h}$. After evaporation, the residue was dissolved in EtOAc, and the organic phase was washed with $\mathrm{HCl}(1 \mathrm{~N})$, water, saturated $\mathrm{Na}_{2} \mathrm{CO}_{3}$ solution, brine, and water. The organic layer was dried over sodium sulfate, filtered, and evaporated. The remaining oil was purified by chromatography using a mixture of $\mathrm{CH}_{2} \mathrm{Cl}_{2} /$
$\mathrm{MeOH}(99: 1)$ as eluent. Evaporation of the pooled fractions yielded $2.5 \mathrm{~g}$ (3.1 mmol, 84\%) of compound $5 .{ }^{13} \mathrm{C}$ NMR: $\delta=172.66$ (Lys, COOMe), $170.41(\mathrm{CONH}) ; 156.51$ (OCONH), 144.04 (Fmoc, C-10/11), 141.73 (Fmoc, C-12/ 13), 140.12 (Chol, C-3), 127.68 (Fmoc, C-3/6), 127.04 (Fmoc, C-2/7), 125.07 (Fmoc, C-1/8), 122.28 (Chol, C-4), 119.97 (Fmoc, C-4/5), 80.39 (Chol, C-1), 67.47 (Fmoc, $\mathrm{CH}_{2} \mathrm{O}$ ), $66.52\left(\mathrm{Chol}, \alpha-\mathrm{CH}_{2}\right), 56.66$ (Chol, C-7), 56.08 (Chol, C-10), 52.38 (Lys, $\mathrm{CH}_{3} \mathrm{O}$ ), 51.14 (Lys, $\left.\alpha-\mathrm{CH}\right) 50.01$ (Chol, C-14), 47.22 (Fmoc, C-9), 42.24 (Chol, C-11), 40.61 (Lys, $\epsilon-\mathrm{CH}_{2} \mathrm{NH}$ ), 39.67; 39.45; 38.82 (Chol, C-2; C-12; C-24), 36.93 (Chol, C-16), 36.69 (Chol, C-15), 36.12 (Chol, C-22), 35.69 (Chol, C-20), 32.26 ( $\left.\beta-\mathrm{CH}_{2}(\mathrm{Lys})\right), 31.80$ (Chol, C-5, C-6), $29.62\left(\delta-\mathrm{CH}_{2}(\mathrm{Lys})\right), 28.13 ; 28.01 ; 27.92$ (Chol, C-17; C-9; C-25), 24.19; 23.73 (Chol, C-8; C-23), 22.73; 22.46 (Chol, C-26; C-27), 22.34 ( $\gamma-\mathrm{CH}_{2}(\mathrm{Lys})$ ) 20.97 (Chol, C-13), 19.27 (Chol, C-18), 18.63 (Chol, C-21), 11.74 (Chol, C-19). Mass calcd for $[\mathrm{M}+\mathrm{Cl}]^{-} \mathrm{C}_{51} \mathrm{H}_{72} \mathrm{~N}_{2} \mathrm{O}_{6} \mathrm{Cl}_{1}$ : 843.5078, found: (ESI-): 843.5049.

No-Fmoc-N $\epsilon$-cholesterylacetyl-lysine (6). The cleavage of the methyl ester was carried as described in the literature (12). To compound $\mathbf{5}$ ( $1.5 \mathrm{~g}, 1.8 \mathrm{mmol}, 1$ equiv) in $20 \mathrm{~mL}$ of THF at $0{ }^{\circ} \mathrm{C}$ was added $0.2 \mathrm{~N} \mathrm{LiOH}(18 \mathrm{~mL}$, $3.6 \mathrm{mmol}, 2$ equiv), and the reaction was stirred for 40 min. To the reaction mixture, $50 \mathrm{~mL}$ of a biphase of 0.2 $\mathrm{N} \mathrm{HCl} /$ EtOAc (1:1) was added, aqueous layer was extracted three times with EtOAc, and the combined organic layers were dried over $\mathrm{MgSO}_{4}$, filtered, and evaporated to dryness. The remaining product was purified by column chromatography on silica gel with a $\mathrm{CH}_{2-}$ $\mathrm{Cl}_{2} / \mathrm{MeOH}$ mixture (95:5) as eluent, yielding $1.1 \mathrm{~g}(1.4$ mmol, $77 \%$ ) of the title compound. ${ }^{13} \mathrm{C} \mathrm{NMR:} \delta=174.78$ (Lys, COOH), 171.14 (CONH); 156.51 (OCONH), 144.01 (Fmoc, C-10/11), 141.37 (Fmoc, C-12/13), 140.06 (Chol, C-3), 127.71 (Fmoc, C-3/6), 127.07 (Fmoc, C-2/7), 125.10 (Fmoc, C-1/8), 122.31 (Chol, C-4), 120.00 (Fmoc, C-4/5), 80.46 (Chol, C-1), 67.31 (Fmoc, $\mathrm{CH}_{2} \mathrm{O}$ ), 66.52 (Chol, $\alpha-\mathrm{CH}_{2}$ ), 56.63 (Chol, C-7), 56.08 (Chol, C-10), 51.47 (Lys, $\alpha-\mathrm{CH}) 49.98$ (Chol, C-14), 47.19 (Fmoc, C-9), 42.24 (Chol, C-11), 40.58 (Lys, $\epsilon-\mathrm{CH}_{2} \mathrm{NH}$ ), 39.67; 39.45; 38.82 (Chol, C-2; C-12; C-24), 36.90 (Chol, C-16), 36.69 (Chol, C-15), 36.12 (Chol, C-22), 35.72 (Chol, C-20), 32.26 ( $\beta-\mathrm{CH}_{2}(\mathrm{Lys})$ ), 31.80 (Chol, C-5, C-6), 29.62, $29.19\left(\delta-\mathrm{CH}_{2}(\mathrm{Lys})\right), 28.16$; 28.01; 27.92 (Chol, C-17; C-9; C-25), 24.19; 23.76 (Chol, C-8; C-23), 22.73; 22.46 (Chol, C-26; C-27), $22.34\left(\gamma-\mathrm{CH}_{2^{-}}\right.$ (Lys)), 20.97 (Chol, C-13), 19.24 (Chol, C-18), 18.63 (Chol, C-21), 11.74 (Chol, C-19). Mass calcd for $[\mathrm{M}-\mathrm{H}]^{-} \mathrm{C}_{50} \mathrm{H}_{69} \mathrm{~N}_{2}$ $\mathrm{O}_{6}$ : 793.5155, found: (ESI-): 793.5143.

Solid-Phase Synthesis. Peptide Synthesis. Synthesis of the conjugates was performed on the LCAA-CPG carrier. For each amino acid or compound to be coupled, different reaction conditions were applied. After every reaction, the solution was filtered and the beads were washed with DMF (two times), $\mathrm{CH}_{2} \mathrm{Cl}_{2}$ (2 times), and acetonitrile (two times). The beads were dried, and Fmocor MMTr- substitution levels were determined. Hereto, an accurately measured quantity of resin was suspended in exactly $25 \mathrm{~mL}$ of $20 \%$ piperidine in $\mathrm{DMF}$ or in $\mathrm{a} \mathrm{HClO}_{4} /$ EtOH mixture (3:2), respectively. After $15 \mathrm{~min}$ the absorbance was measured at $300 \mathrm{~nm}$ for fulvene (or adduct) determination and at $475 \mathrm{~nm}$ for methoxytrityl cation detection $\left(\epsilon_{\mathrm{Fmoc}}=7500, \epsilon_{\mathrm{MMTr}}=55000\right)$. If the coupling yields were unsatisfactory, a second coupling reaction was performed. Before each new coupling, the remaining amino groups were capped using $1.5 \mathrm{~mL}$ of $20 \%$ acetic anhydride in THF and $1.5 \mathrm{~mL}$ of $20 \%$ 1-methylimidazole and 40\% 2,4,6-trimethylpyridine in THF for $15 \mathrm{~min}$, and washed with acetonitrile and DMF. Fmoc-deprotection was carried out with a piperidine/ 
DMF mixture $(2: 8 \mathrm{v}: \mathrm{v}, 2 \mathrm{~mL})$ for $5 \mathrm{~min}$ and washing for 15 min, while for MMTr-deprotection, 3\% TCA in $\mathrm{CH}_{2-}$ $\mathrm{Cl}_{2}$ was used 3 to 4 times for $3 \mathrm{~min}$, until no yellow color was detectable.

Coupling of Fmoc-sarcosine to LCAA-CPG was generally performed as described in the literature (13). To a solution of Fmoc-sarcosine (116 mg, $0.37 \mathrm{mmol}, 4$ equiv), HOBt (31 mg, $2.23 \mathrm{mmol}, 2.5$ equiv), and HBTU ( $88 \mathrm{mg}$, $0.23 \mathrm{mmol}, 2.5$ equiv) in $2 \mathrm{~mL} \mathrm{DMF}$ was added DIEA ( $78 \mu \mathrm{L}, 0.46 \mathrm{mmol}, 5$ equiv), and the mixture was shaken for 5 min. More DIEA ( $78 \mu \mathrm{L}, 0.46 \mathrm{mmol}, 5$ equiv) was added, and the solution was then poured onto LCAA-CPG beads ( $1 \mathrm{~g}, 92 \mu \mathrm{mol}, 1$ equiv). The reaction mixture was occasionally shaken for $2 \mathrm{~h}$. Coupling of MMTr-butyric acid was obtained by adding a solution of 4-OMMTrbutyric acid (14) (220 mg, $0.46 \mathrm{mmol}, 5$ equiv), HOBT/ HBTU ( $88 \mathrm{mg}, 0.23 \mathrm{mmol}, 2.5$ equiv), and DIEA (158 $\mu \mathrm{L}$, $0.92 \mathrm{mmol}, 10$ equiv) in $2 \mathrm{~mL}$ of DMF. Following deprotection of MMTr, Fmoc-glycine was coupled to the 4-OH group of 4-OH-butyric acid by occasionally swirling the beads with a reaction mixture of Fmoc-glycine (273 $\mathrm{mg}, 0.92 \mathrm{mmol}, 10$ equiv), DIC $(72 \mu \mathrm{L}, 0.46 \mathrm{mmol}, 5$ equiv), and DMAP (17 mg, $13.8 \mu \mathrm{mol}, 0.15$ equiv) in DMF (2 mL).

The cholesterylacetamide 6 was attached to glycine by using a solution of 6 ( $0.29 \mathrm{mg}, 0.37 \mathrm{mmol}, 4$ equiv), HBTU (140 mg, $0.37 \mathrm{mmol}, 4$ equiv), HOBt ( $49 \mathrm{mg}, 0.37 \mathrm{mmol}$, 4 equiv), and DIEA ( $168 \mu \mathrm{L}, 0.92 \mathrm{mmol}, 10$ equiv) in 1 $\mathrm{mL}$ of DMF. The mixture was shaken for 5 min before it was added to the Fmoc-deprotected support (yield: 90\%).

For single oligonucleotide loading, 4-O-MMTr-butyric acid was coupled as a linker before starting oligonucleotide synthesis. For the branching-off purposes, N $\alpha-\mathrm{Fmoc}-$ $\mathrm{N} \epsilon$-Fmoc-lysine (4 equiv) was used. The protected lysine was attached to the support by adding a solution of HBTU (4 equiv), HOBt (4 equiv), and DIEA (10 equiv) in DMF. Subsequently, 4-O-MMTr-butyric acid was coupled. The amount of 4-O-MMTr-butyric acid used was always 4 times the amount of free $\mathrm{NH}_{2}$ groups available for coupling.

Oligonucleotide Synthesis. Four different supports were used for assembly of the undeca- and octadecamers. The number of hydroxyl groups per gram of support was determined by detritylation and amounted to 48,80 , and $130 \mu \mathrm{mol} / \mathrm{g}$ for the supports $\mathbf{9}, \mathbf{1 1}, \mathbf{1 3}$, respectively. The assembly of oligonucleotides was done on the Expedite following a standard $1 \mu \mathrm{mol}$ protocol, using only $0.5 \mu \mathrm{mol}$ of support and a 4 min coupling time. Following deprotection with AMA (methylamine-ammonia 1:1) for $2 \mathrm{~h}$ at $25^{\circ} \mathrm{C}$, the products were purified by gel filtration using $30 \%$ aqueous acetonitrile to avoid adsorption of the cholesteryl moieties to the support. Depending whether a single, double, or four chains of oligonucleotides needed to be coupled to the cholesterol moiety, one of the different supports $\mathbf{9}, \mathbf{1 1}, \mathbf{1 3}$ were used. The conjugates could be purified by RP-HPLC on PLRP-S (100 A, $8 \mu \mathrm{M}$, $250 \times 7 \mathrm{~mm}$, Polymer Laboratories) with a $\mathrm{CH}_{3} \mathrm{CN}$ gradient in $0.05 \mathrm{M}$ ammonium acetate, $\mathrm{pH}$ 7.0. In general, in ascending order, tetrameric oligo-containing dendrimer eluted before the trimer, dimer, and monomer species. Analysis was accomplished by HPLC/MS on a capillary chromatograph (CapLC, Waters, Milford, CA). Columns of $150 \mathrm{~mm} \times 0.3 \mathrm{~mm}$ length (LCPackings, San Francisco, CA) were used. Oligonucleotides were eluted with a triethylammonium-1,1,1,3,3,3-hexafluoro-2-propanol:acetonitrile solvent system, and the flow rate was $5 \mu \mathrm{L} / \mathrm{min}$. Electrospray spectra were acquired on a quadrupole orthogonal acceleration/time-of-flight mass spectrometer (Q-Tof-2, Micromass, Manchester, U.K.) in
Table 1. Results of Mass Spectrometry Analysis of the Monomeric (10), Dimeric (12), and Tetrameric (14) Constructs

\begin{tabular}{lrrrrr}
\hline & \multicolumn{2}{c}{ a series } & & \multicolumn{2}{c}{ b series } \\
\cline { 2 - 3 } \cline { 5 - 6 } & \multicolumn{1}{c}{ calcd } & \multicolumn{1}{c}{ found $^{c}$} & & calcd & \multicolumn{1}{c}{ found $^{c}$} \\
\hline monomer & $6433.4^{a}$ & 6432.8 & & $4226.1^{a}$ & 4225.8 \\
dimer & $12358.4^{b}$ & 12356.4 & & $7937.8^{a}$ & 7937.2 \\
tetramer & $24202.6^{b}$ & ND $^{d}$ & & $15368.9^{b}$ & 15367.0
\end{tabular}

${ }^{a}$ Monoisotopic mass. ${ }^{b}$ Average mass. ${ }^{c}$ Mass obtained after deconvolution of the electrospray spectrum. ${ }^{d}$ ND: not determined

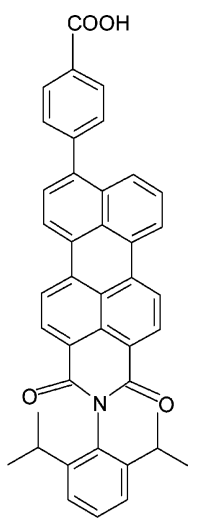

Figure 3. Structure of the perylene monoimide derivative used as a membrane probe.

negative ion mode. The scan time used was $2 \mathrm{~s}$. The combined spectra from a chromatographic peak were deconvoluted using the MaxEnt algorithm of the software Masslynx 3.4 (Micromass). Theoretical oligonucleotide masses were calculated using the monoisotopic element masses for masses up to 8000 and using the average element masses for masses above 8000 . The data are given in Table 1.

Fluorescence Resonance Energy Transfer (FRET) Measurements. Lipofectamine 2000 was diluted in PBS (phosphate buffer saline, $\mathrm{pH}=7.4$ ) (Sigma) and was labeled with a perylene monoimide derivative (PMI$\mathrm{COOH}$ ) (Figure 3) in an approximate ratio of 1 fluorescent molecule for 250 lipid molecules. Hybridization between the antisense oligonucleotide labeled with TMR and the DNA with or without cholesterol was performed by heating appropriate amounts in $\mathrm{PBS}$ at $80^{\circ}$ for $3 \mathrm{~min}$, followed by cooling at room temperature for $15 \mathrm{~min}$. Hybridized DNA was added in increasing concentrations to the Lipofectamine suspension. The fluorescence energy transfer between PMI-COOH and TMR was monitored by exciting the sample at $450 \mathrm{~nm}$ (where the direct excitation of TMR is minimal) and measuring the fluorescence quenching of $\mathrm{PMI}-\mathrm{COOH}$ at the maximum emission peak $(549 \mathrm{~nm})$. The values were corrected for the nonlabeled DNA quenching of PMI-COOH fluorescence and for the TMR emission at $549 \mathrm{~nm}$.

Cells. NIH 3T3 cells stably transfected with a plasmid containing the human $m d r 1$ gene (pSK1 MDR) were gift from M. M. Gottesman. The MDR-3T3 cells were grown in DMEM (Dulbecco minimal cututred media) medium containing $10 \%$ FBS (fetal bovine serum) and $60 \mathrm{mg} / \mathrm{mL}$ colchicine.

Treatment of Cells with Antisense Oligonucleotides. The experimental protocols were similar to those previously described (11). Briefly, MDR 3T3 cells were grown in $162 \mathrm{~mm}$ flasks to $95 \%$ confluency and then seeded onto six-well plates at $3 \times 10^{5} /$ well in $10 \% \mathrm{FBS} /$ DMEM and incubated $24 \mathrm{~h}$. The cells were washed twice with PBS. Complexes between dendrimers and antisense 
strand were prepared in $10 \mathrm{mM}$ TRIS, $50 \mathrm{mM}$ NaCI, 1 mM EDTA by heating the solutions at $80^{\circ} \mathrm{C}$ and cooling to room temperature for $15 \mathrm{~min}$. The complexation of the double stranded dendrimeric form of the antisense was done with Lipofectamine 2000 (Invitrogene) in OptiMEM according to standard procedure. The complexes were added to cells in 10\% FBS/DMEM. The cells were incubated with complexes for $4 \mathrm{~h}$. Then the cells were rinsed and further incubated for $68 \mathrm{~h}$ in $2 \% \mathrm{FBS} / \mathrm{DMEM}$. All conditions were performed in triplicate. The Pglycoprotein percent shift is calculated from the lipofectamine 2000 control shift.

Pharmacological Effects of Antisense Treatment. Analysis of the pharmacological effects of dendrimeric delivery was based on a previously described assay (15) involving antisense inhibition of P-glycoprotein expression in mouse 3T3 cells stably transfected with the human MDR1 gene. The cell surface expression of P-glycoprotein was determined by immunostaining and quantitation by flow cytometry, as described (16). Briefly, the MRK16 anti-P-glycoprotein antibody (Kamiya Biochemicals), which is directed against an external epitope, was employed as the primary antibody. After the incubation, the cells were washed twice in $10 \% \mathrm{FBS} / \mathrm{PBS}$. The level of phycoerythrin (PE)-conjugated goat anti-mouse IgG (Sigma, St. Louis, MO was used as the second antibody) in viable cells (viability determined by light scatter) was quantitated using the Summit V3.0 software application (Cytomation Inc.) on a Becton Dickinson flow cytometer.

\section{RESULTS AND DISCUSSION}

Synthesis. For the synthesis of the monomeric, dimeric, and tetrameric cholesterol oligonucleotide conjugates, a strategy was used based on lysine chemistry. Lysine has an $\alpha$ - and $\epsilon$-amino group, and binding of one lysine unit via its $\alpha$ carboxyl function to a solid support allows the two functional amino groups to be used for oligonucleotide synthesis.

Cholesterol (1) was derivatized at its C-3 hydroxyl group with a functional group that is stable against acid and base and that can be used for the formation of an amide bond (Scheme 1). Reaction of cholesterol with chloroacetic acid in the presence of $\mathrm{NaH}$ gives poor yields. Therefore, cholesterol was first reacted with the diethylacetal of bromoacetaldehyde in the presence of $\mathrm{NaH}$ in a mixture of THF/DMF for $18 \mathrm{~h}$ at $85{ }^{\circ} \mathrm{C}$. In this way cholesterylacetaldehyde diethylacetal (2) was obtained in $70 \%$ yield. Reaction of $\mathbf{2}$ with Jones reagent resulted in the formation of the desired cholesterylacetic acid $\mathbf{4}$, but the reaction went to completion only after $24 \mathrm{~h}$, and multiple side products were formed. To avoid side reactions, the acetal was first hydrolyzed with trifluoroacetic acid in dichloromethane for $4 \mathrm{~h}$, giving the aldehyde $\mathbf{3}$. The oxidation of the aldehyde to the carboxylic acid with Jones reagent was completed after $10 \mathrm{~min}$, giving a clean reaction product. The oxidation using hypochlorite was less effective.

Subsequently, Fmoc-Lysine-OMe was coupled with its free $\epsilon-\mathrm{NH}_{2}$-group to cholesteryl acetic acid using HATU, DIEA, and TEA (Scheme 1). Compound 5 was then deprotected by hydrolyzing the methyl ester with $0.2 \mathrm{~N}$ $\mathrm{LiOH}$ in $\mathrm{THF} / \mathrm{H}_{2} \mathrm{O}$. The carboxylic acid of 6 could then be used to couple 6 to the solid support 7. This solid support material was obtained by derivatization of LCAA-CPG with sarcosine. Subsequently, MMTr-O-butyric acid was attached to the sarcosine and detritylated
Scheme 1. Synthesis of Cholesterol-Conjugated Lysine on Solid Support ${ }^{a}$
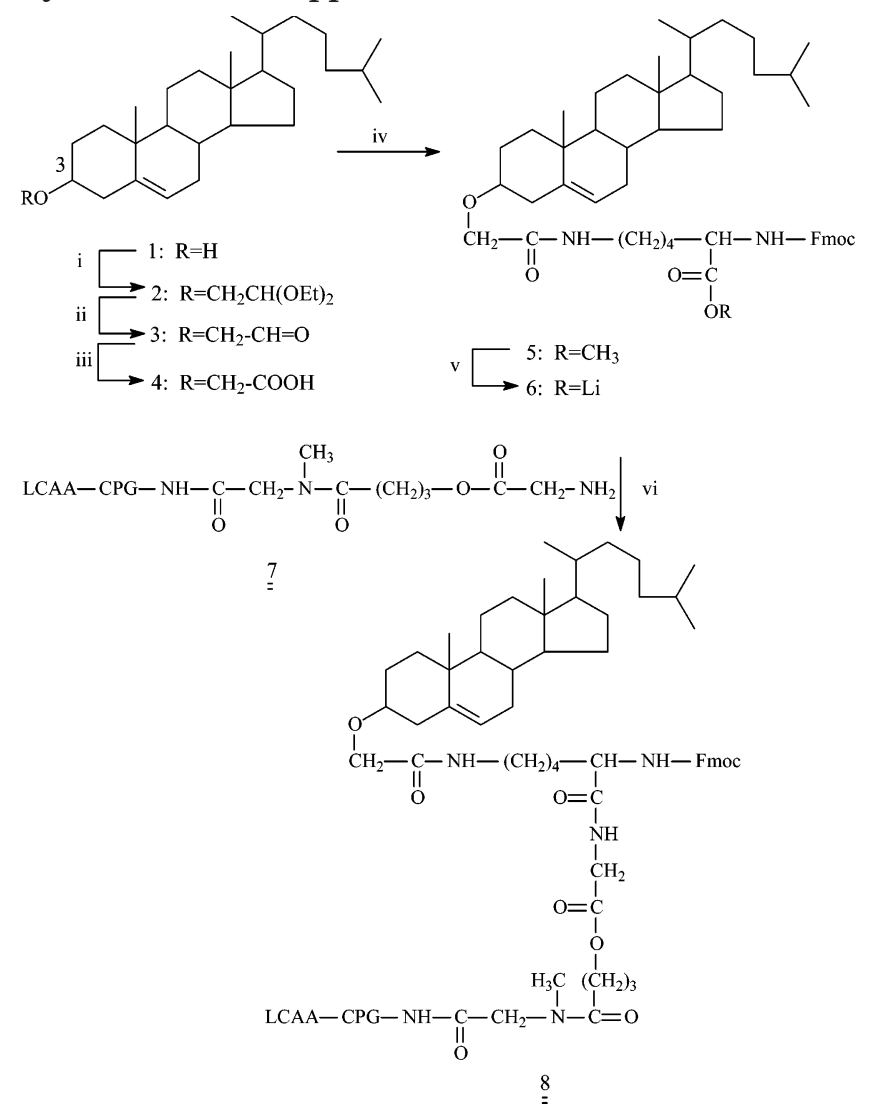

${ }^{a}$ i: $\mathrm{BrCH}_{2} \mathrm{CH}(\mathrm{OEt})_{2}, \mathrm{NaH}, \mathrm{DMF} / \mathrm{THF}$; ii: $\mathrm{CF}_{3} \mathrm{COOH}$ aqueous in DCM; iii: $\mathrm{CrO}_{3}, \mathrm{H}_{2} \mathrm{SO}_{4}, \mathrm{CH}_{3} \mathrm{COCH}_{3}, \mathrm{H}_{2} \mathrm{O}$; iv: Fmoc-LysineOMe HCL, HATU, DIEA, DMF; v: $\mathrm{LiOH}$, THF, $\mathrm{H}_{2} \mathrm{O}$; vi: HBTU, HOBT, DIEA, DMF.

with trifluoroacetic acid. The free hydroxyl group was used for coupling with Fmoc-glycine with formation of a base-labile ester bond. After Fmoc deprotection, compound 6 was coupled to the solid support 7 using a mixture of HBTU, HOBT, and DIEA (Scheme 1). In this way, a cholesterol-derivatized lysine connected to a solid support via an ester bond was obtained, as general support for the synthesis of the desired oligonucleotide monomers $(\mathbf{1 0 a}, \mathbf{b})$ and dendrimers $(\mathbf{1 2 a}, \mathbf{b}$ and $\mathbf{1 4 a}, \mathbf{b})$.

The synthesis of the cholesteryl-lysyl oligonucleotide (monomer 10a,b) is shown in Scheme 2. After Fmoc deprotection of 8, coupling of MMTr-O-butyric acid, and MMTr deprotection, the solid material 8 was used for oligonucleotide synthesis with the phosphoramidite approach. An 11-mer and 18-mer were assembled with a sequence complementary to the antisense oligonucleotide.

Deprotection using AMA reagent (concentrated aq ammonia-aq methylamine 1:1) yielded $\mathbf{1 0 a}, \mathbf{b}$. The conjugate was concomitantly removed from the solid support by cleavage of the labile ester group with formation of the methylamide (with 5\% amide formation according to MS analysis).

Branching of the peptide linker was carried out by coupling of Fmoc-protected lys-OH on deprotected 8 (Scheme 3). After a second deprotection step and binding of hydroxybutyric acid, the solid support can be used for the synthesis of two oligonucleotides on the same cholesteryl derivatized peptide (Scheme 3). Repetition of the protocol of coupling Fmoc-protected lys-OH, Fmoc deprotection, and coupling of hydroxybutyric acid might lead to an exponential branching of the cholesterol-derivatized 
Scheme 2. Synthesis of Cholesterol-Modified Oligonucleotide Monomers ${ }^{a}$

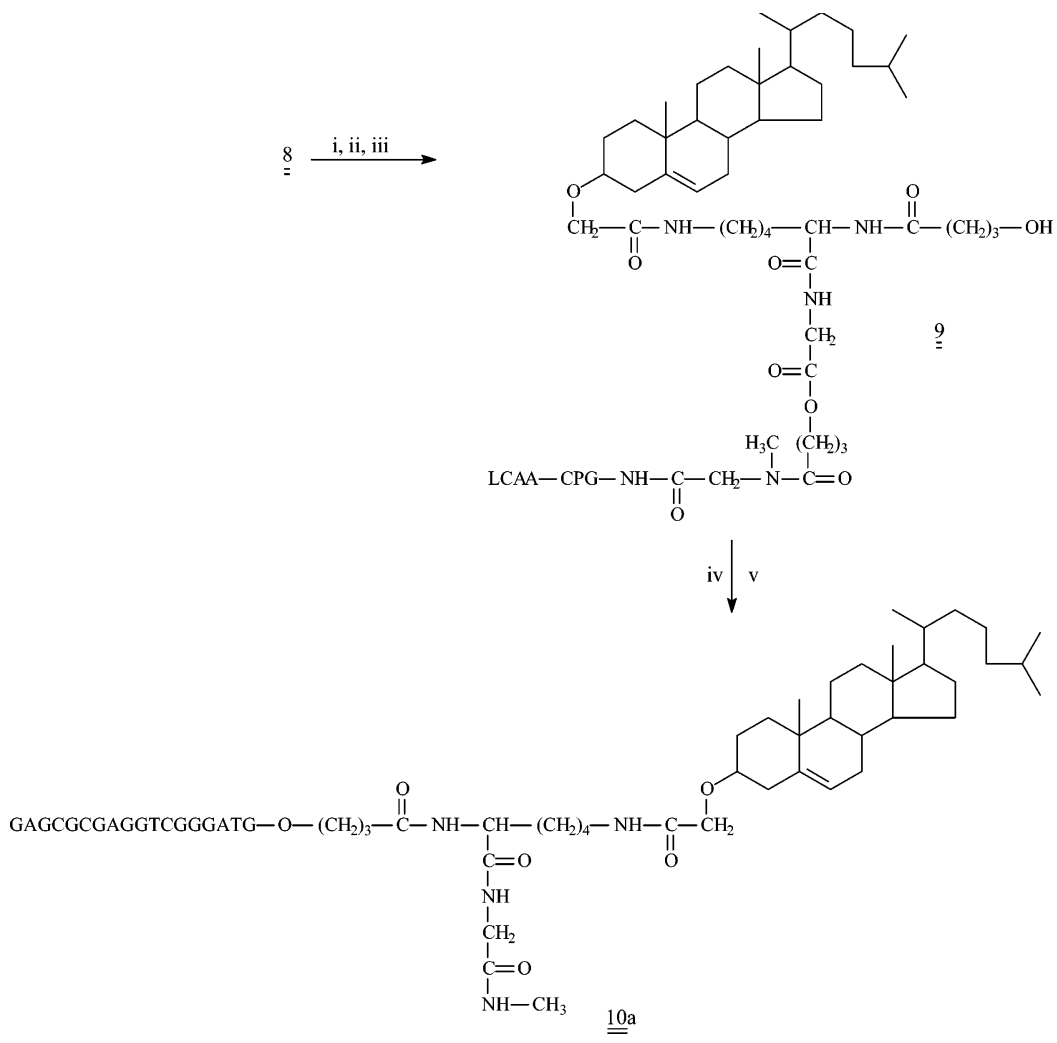

${ }^{a}$ i: piperidine, DMF; ii: $\mathrm{MMTrO}\left(\mathrm{CH}_{2}\right)_{3} \mathrm{COOH}, \mathrm{HOBt}$, HBTU, DIEA, DMF; iii: $\mathrm{CCl}_{3} \mathrm{COOH}$, DCM; iv: oligonucleotide synthesis; v: deprotection (aq. $\mathrm{CH}_{3} \mathrm{NH}_{2}-\mathrm{NH}_{3}$ ) 10b: same molecule with oligo sequence: AGGTCGGGATG-.

\section{Scheme 3. Synthesis of Cholesterol-Modified Oligonucleotide Dimers ${ }^{a}$}

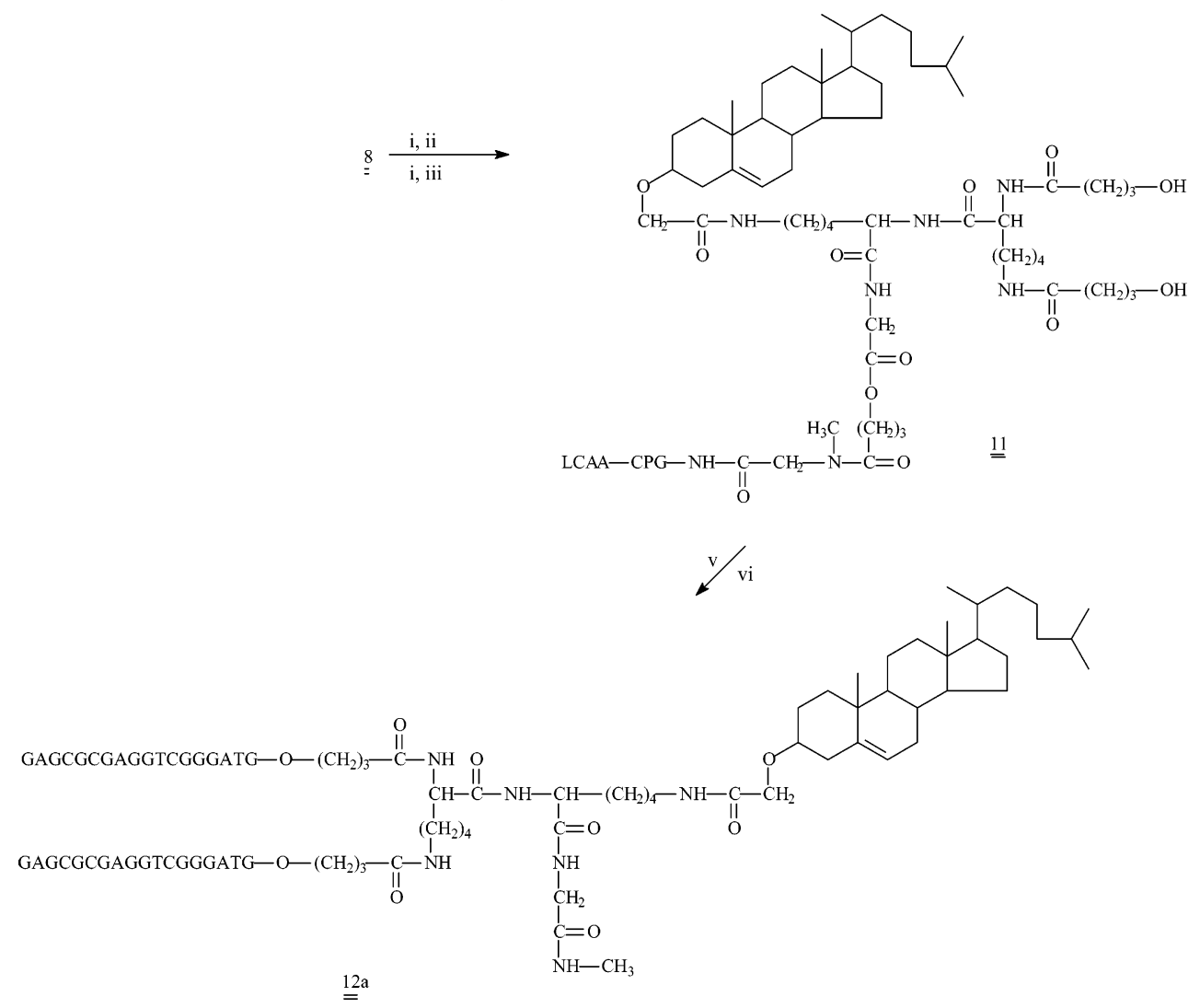

${ }^{a}$ i: piperidine, DMF; ii: (Fmoc) $)_{2}$ lys-OH, HBTU, HOBT, DIEA, DMF; iii: $\mathrm{MMTrO}\left(\mathrm{CH}_{2}\right)_{3} \mathrm{COOH}, \mathrm{HOBT}, \mathrm{HBTU}$, DIEA, DMF; iv: $\mathrm{CCl}_{3} \mathrm{COOH}$, DCM; v: oligonucleotide synthesis; vi: deprotection (aq. $\mathrm{CH}_{3} \mathrm{NH}_{2}-\mathrm{NH}_{3}$ ) 12b: same construct with oligo sequence: AGGTCGGGATG-. 


\section{Scheme 4. Synthesis of Cholesterol-Modified Oligonucleotide Tetramers ${ }^{a}$}

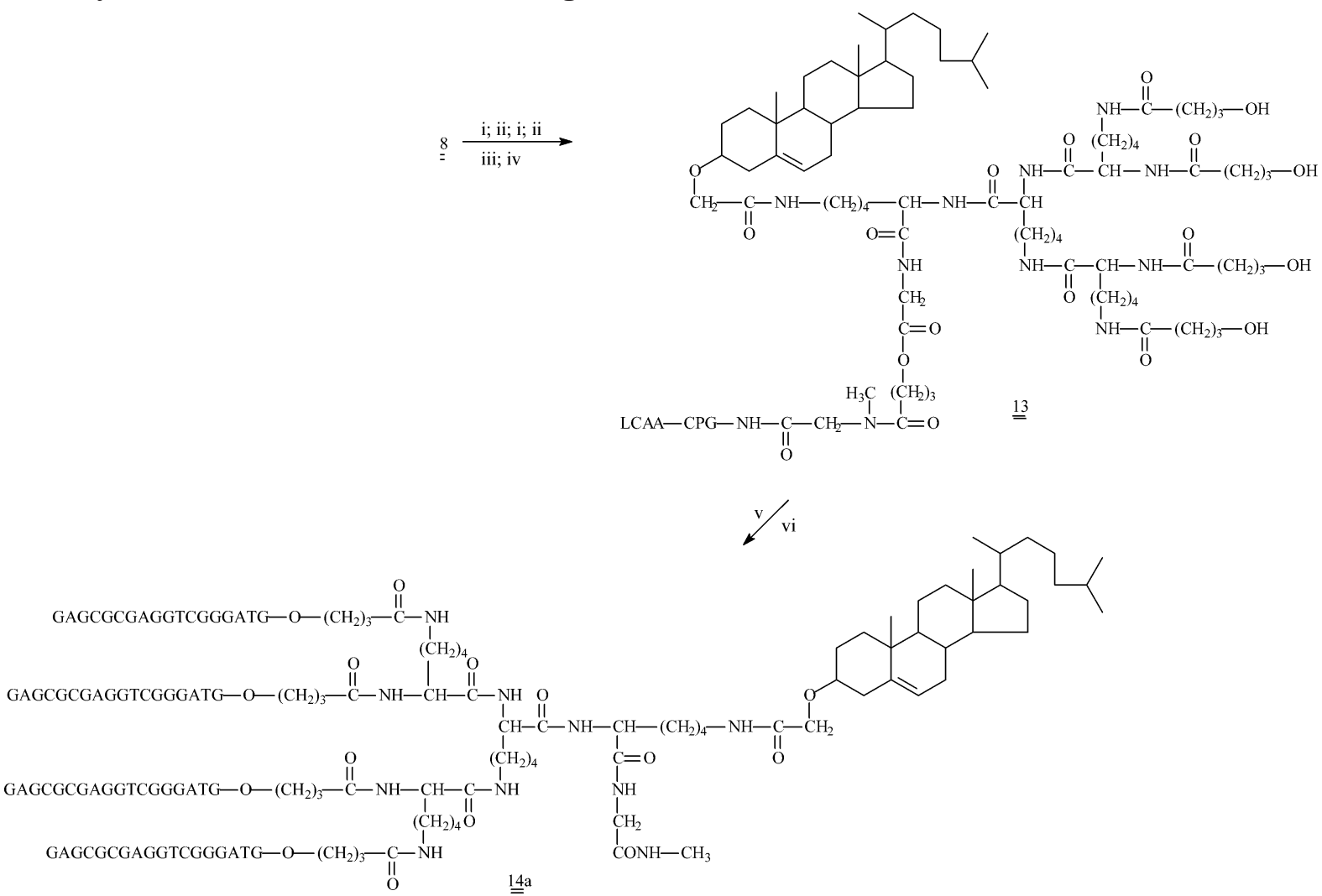

${ }^{a}$ i: piperidine, DMF; ii: (Fmoc) $)_{2}$ lys-OH, HBTU, HOBT, DIEA, DMF; iii: MMTrO $\left(\mathrm{CH}_{2}\right)_{3} \mathrm{COOH}$, HOBT/HBTU, DIEA, DMF; iv: $\mathrm{CCl}_{3} \mathrm{COOH}$, DCM; v: oligonucleotide synthesis; vi: deprotection procedure (aq. $\mathrm{CH}_{3} \mathrm{NH}_{2}-\mathrm{NH}_{3}$ ). 14b: same construct with oligo sequence: AGGTCGGGATG.

solid support, enabling the assembly of multiple oligonucleotides on one cholesterol moiety. This is demonstrated with the branched dendrimer 14a,b in Scheme 4. However, mass spectral analysis of the major fraction shows that only three of the four hydroxybutyryl moieties are used for oligonucleotide synthesis. The HPLC sample of the trimeric compound shows only a small fraction of the four-branched dendrimer. The three-branched molecule has an acetylated lysine moiety (although it is not clear if acetylation has occurred at the $\alpha-\mathrm{N}$ or the $\epsilon-\mathrm{N}$ of lysine). Apparently, steric hindrance or the occurrence of a side reaction hampers the formation of the fourbranched construct. We were able, however, to isolate sufficient amounts of the tetrameric construct by chromatographic purification to carry out biological tests.

Using these three different supports, cholesterol oligonucleotide complexes were formed in a ratio of $1: 1$ $(\mathbf{1 0 a}, \mathbf{b}), 1: 2(\mathbf{1 2 a}, \mathbf{b})$, and 1:4 $(\mathbf{1 4 a}, \mathbf{b})$, and the obtained products were used for hybridization with the antisense oligonucleotide followed by cationic liposome complexation. Although it is difficult to analyze the way the antisense oligonucleotides are associated to the sensedendrimers, the stability of the complex was determined using melting experiments. In all cases, the melting point was above $70{ }^{\circ} \mathrm{C}$, demonstrating that stable complexes are formed.

Lipoplexes Formation Followed by FRET. The dynamics of DNA-liposomes interaction can be monitored in a FRET experiment due to the sixth power dependence of the fluorescence energy transfer efficiency to the distance between donor and acceptor. The process can thus take place on distances of a few nanometers, meaning that only the DNA bound to the surface of liposomes will contribute to the variation of the measured signal. The FRET approach was used to investigate the association between DNA and liposomes with different compositions (17), to follow in time the changes in lipidDNA interaction during lipoplex formation (18), or to monitor the oligonucleotide release into living cells (19). Theoretical calculations of FRET efficiency particularly applied for the geometry of lipoplexes were also developed (20).

In the context of our ongoing study of perylene monoimide derivatives in biological systems, this type of fluorescent molecule has been used in these experiments for several reasons. Due to its hydrophobic rylene core, the molecule is rapidly incorporated into a lipid bilayer, while the hydrophilic carboxylic group most probably anchors the molecule at the phospholipid-water interface. This dye was chosen instead of other fluorescent probes for membranes (e.g. diphenyl hexatriene DPH or its derivatives) because of the very high fluorescence quantum yield (almost 1) and the high photostability in hydrophobic environments of the PMI chromophore (21), making possible the detection of fluorescence intensity variations at very low concentrations $\left(10^{-8}-10^{-7} \mathrm{M}\right)$. The molecule is practically devoid of fluorescence in water, so the dye that was not incorporated into liposomes does not contribute to the total intensity measured (ongoing study). In addition, the carboxylic group is negatively charged at the $\mathrm{pH}$ used for these experiments ( $\mathrm{pH} \mathrm{7.4),}$ which makes the interaction with the positively charged lipids composing the Lipofectamine more efficient when compared to an indocarbocyanine dye with two long alkyl chains (DiI-C18) (data not shown). Third, the high spectral overlap between the PMI-COOH emission and TMR absorption (Figure 4) makes this dye pair very good for FRET measurements. 


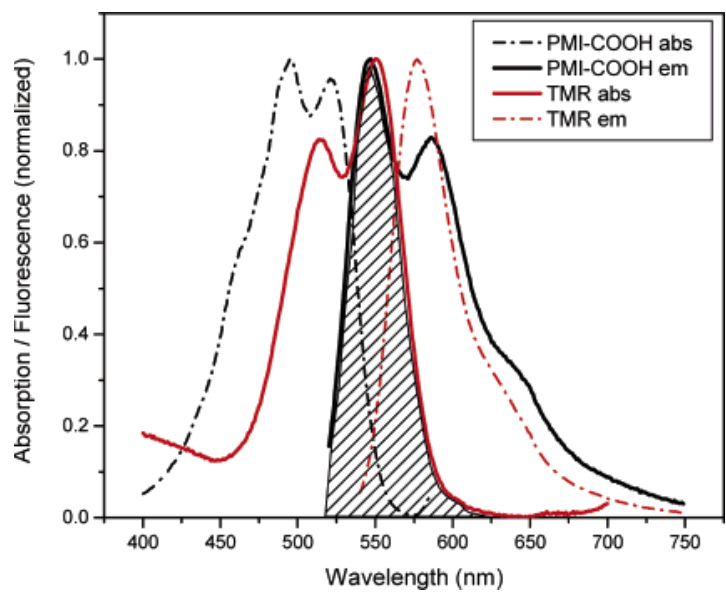

Figure 4. Absorption and emission spectra for PMI-COOH and TMR. The filled area represents the overlap between the emission spectrum of PMI-COOH and the absorption spectrum of TMR. The overlap integral calculated according to the Förster relation (22) is $J=5.2 \times 10^{-13} \mathrm{~cm}^{6} \mathrm{mmol}^{-1}$ and the Förster radius is $\approx 60 \AA$.

The purpose of our experiments was to observe if cationic liposomes (Lipofectamine) are able to complex more antisense DNA hybridized with the cholesterolmodified sense sequence than the same DNA hybridized with the normal sense oligonucleotide (10). Lipofectamine suspension labeled with the donor (PMI-COOH) was kept at constant concentration in all experiments, while increasing acceptor concentrations (hybridized TMRDNA) were added to the sample. Figure $5 \mathrm{a}$ and $\mathrm{b}$ show the averages and the standard deviations obtained from three independent experiments for each double strand type [naked DNA (11 DNA and $18 \mathrm{DNA}$ ) and cholesterolmodified monomeric $(\mathbf{1 0 a}, \mathbf{b})$, dimeric $(\mathbf{1 2 a}, \mathbf{b})$, and tetrameric (14a,b) DNA were evaluated]. The intensity of the donor in the presence of the acceptor $\left(I_{\mathrm{DA}}\right)$ was normalized to the initial intensity of the donor $\left(I_{\mathrm{D}}\right)$. Using a logarithmic scale, the first data points in each determination could be linearly fitted, and the values obtained for the slopes are given in Table 2.

As can be observed, hybridizing the 20-mer sequence with the cholesterol-modified sense 11-mer oligonucleotides $(\mathbf{1 0 b}, \mathbf{1 2 b}, \mathbf{1 4 b})$ shifts the slopes of the linear fitting toward higher values when compared to the unmodified sense sequence. Assuming that each TMR molecule acts as an independent acceptor even when two (12b) or four (14b) DNA oligonucleotides are linked in the same
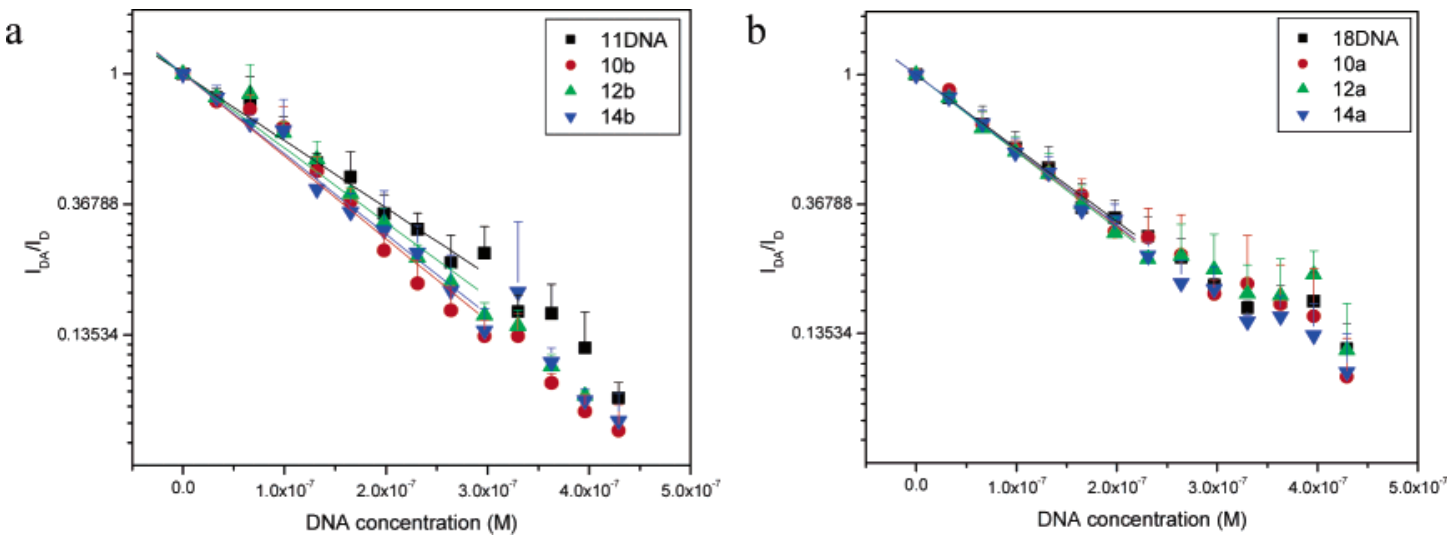

Figure 5. Quenching of PMI-COOH fluorescence (labeling Lipofectamine) using the 11 (a) and the 18 (b) oligonucleotide sequence for hybridization of the TMR-antigene sequence. The intensity of the donor in the presence of the acceptor $\left(I_{\mathrm{DA}}\right)$ was normalized to the initial intensity of the donor $\left(I_{\mathrm{D}}\right)$. Note that logarithmic scale was used. The first data points in each determination could be linearly fitted, and the values obtained for the slopes are given in Table 2. dendrimer, more donor molecules are quenched for the same DNA amount added to the system when cholesterolmodified sequences are used. Thus, the antisense oligonucleotide quantity bound to the liposomes is slightly higher in the case of cholesterol-modified sense oligonucleotides. The differences between the unmodified and the cholesterol-modified sequence are not very pronounced, but they are statistically significant. On the other hand, it seems that the number of oligonucleotides linked to the same cholesterol molecule does not influence the binding. When the 18-mer sense sequence is used for hybridization, no differences in the uptake in lipoplexes can be observed between the cholesterol-modified (10a, 12a, 14a) and the unmodified oligonucleotides. Another observation is that the slope values obtained for the 11and 18-oligonucleotide sequence are not statistically different. Given the small length change from the 11 to the 18 sequences, we can conclude that the electrostatic interaction is the most important factor governing the formation of lipoplexes, while the much weaker hydrophobic interaction due to the presence of cholesterol may have a role in the case of short DNA sequences.

The fact that we were not able to find significant differences in the liposome loading does not necessarily mean that a higher transfection efficiency in living cells cannot be obtained with the cholesterol-modified sequences. Previous studies reported a higher transfection efficiency obtained with cholesterol-modified oligonucleotides by themselves due to an increased binding to the cellular membranes $(23,24)$. It seems thus possible that the uptake and the metabolization pathways, even when using a delivery agent, are different for the cholesterolmodified sequences when compared to the usual ones.

Biological Activity. The biological activity was determined using the $2^{\prime}$-MOE gapmer of phosphorothioate as the antisense strand (Table 3). The concentration was determined spectroscopically. When incubating the antisense oligonucleotide with Lipofectamine 2000, a maximum activity was obtained at $50 \mathrm{nM}$ (giving $42.2 \% \mathrm{P}$-gp shift). Therefore, this antisense concentration was used in further experiments. When the cholesterol dendrimers 
Table 3. Percent Reduction of P-Glycoprotein Expression Level in Mouse 3T3 Cells by Dendrimer-Antisense Complexes $^{a}$

\begin{tabular}{ccccc}
\hline & antisense alone & $\begin{array}{c}\text { dimer } 12 \mathrm{a}+ \\
\text { antisense ratio 1:1 }\end{array}$ & $\begin{array}{c}\text { tetramer 14a }+ \\
\text { antisense ratio 1:1 }\end{array}$ & $\begin{array}{c}\text { dimer 12a }+ \\
\text { tetramer 14a }+ \\
\text { antisense ratio 1:2 }\end{array}$ \\
\hline P-gp & $62.8 \%$ & $68.9 \%$ & $70.5 \%$ & $72.4 \%$
\end{tabular}

${ }^{a} \mathrm{NIH}_{3} \mathrm{~T}_{3}$-MDR cells were transfected with the complexes of 12a or 14a, the antisense oligonucleotide, and Lipofectamine 2000. Results were obtained after $48 \mathrm{~h}$ incubation in $5 \% \mathrm{FBS}$. The ratio between 12a or 14a and the antisense oligonucleotide was 1:1, 1:2, and 1:4. The antisense oligonucleotide was always used at $50 \mathrm{nM}$ concentration.

12a and 14a were tested in complex with the antisense construct but without adding lipofectamine 2000, no significant effect was seen except after very long incubation time $(72 \mathrm{~h})$. This means that the dendrimers alone were not effective in delivering the antisense oligonucleotide. Significant effects were obtained when the dendrimers 12a and 14a were used in the presence of lipofectamine 2000 (Table 3). After $48 \mathrm{~h}$ incubation the antisense oligonucleotide gives $62.8 \% \mathrm{P}$-gp shift, while in the presence of the dendrimers and using 1:1, 1:2, or 1:4 molar ratios of dendrimer and antisense oligonucleotides (fixed at $50 \mathrm{nM}$ ), the P-gp shift varied from $68.9 \%$ to $74.0 \%$. The effect is modest but significant. The biological activity is somewhat increased when the antisense oligonucleotides are more condensed (ratio 1:1 versus ratio $1: 2$ or $1: 4)$.

\section{CONCLUSION}

Using a linker based on lysine chemistry, we were able to synthesize monomeric, dimeric, and tetrameric oligonucleotide constructs covalently linked to a cholesterol moiety. These monomeric and dendrimeric sense DNA were complexed with enzymatic stable antisense oligonucleotides targeting P-glycoprotein expression. Perylene dye was used to monitor uptake of the constructs in cationic lipids. In the case of 11-mer cholesterol-modified sense DNA, a higher amount of antisense oligonucleotide could be incorporated in the cationic liposomes than without cholesterol modification. However, this difference did not exist with the 18-mer cholesterol-modified sense DNA. Also the number of oligonucleotides linked to the same cholesterol moiety does not influence binding to the cationic lipids. In this case, electrostatic interactions seems to play the most important role during complex formations and longer sense DNA gives higher concentration of antisense DNA in the lipoplexes. The previously observed results of the better delivery of duplex oligonucleotide versus single-stranded oligonucleotides (10) may be partially explained by this phenomenon. However, dendrimer delivery of the antisense oligonucleotide using cholesterol-modified 18-mer sense DNA and lipofectamine resulted in a small but significant increase in biological activity. This increase in biological activity is, most probably, due to a difference in intracellular metabolism i.e., the kinetics with which the antisense oligonucleotide is delivered to its target mRNA.

\section{ACKNOWLEDGMENT}

We thank René De Boer for assistance with the mass spectrometric analysis, and Chantal Biernaux and Tom De Roeck for their excellent editorial help. Steven De Feyter is a postdoctoral fellow of the Fund for Scientific Research - Flanders. The Catholic University of Leuven (IDO/02/014) is acknowledged for financial support. Financial support from the University of North Carolina was provided by the grant P01GM59259 to R. L. Juliano. The authors thank the Federal Science Policy through IUAP-V-03, and the Institute for the promotion of innovation by Science and Technology in Flanders (IWT).
Anca Margineanu gratefully acknowledges the Research Foundation of KU Leuven through GOA 2001/2.

\section{LITERATURE CITED}

(1) Scherer, L. J., and Rossi, J. J. (2003) Approaches for the sequence-specific knockdown of mRNA. Nat. Biotechnol. 21, 1457-1465.

(2) Shoji, Y., and Nakashima, H. (2004) Current status of delivery systems to improve target efficacy of oligonucleotides. Curr. Pharm. Des. 10, 785-796.

(3) Boulikas, T. (1996) Liposome DNA delivery and uptake by cells. Oncol. Rep. 3, 989-995.

(4) Bijsterbosch, M. K., Manoharan, M., Dorland, R., Waarlo, I. H., Biessen, E. A., and Van Berkel, T.-J. (2001) Delivery of cholesteryl-conjugated phosphorothioate oligodeoxynucleotides to Kupffer cells by lactosylated low-density lipoprotein. Biochem. Pharmacol. 62, 627-633.

(5) Girão de Cruz, M. T., Simões, S., Pedroso de Lima, M. C. (2004) Improving lipoplex-mediated gene transfer into C6 glioma cells and primary neurons. Exp. Neurol. 187, 65-75.

(6) Zuhorn, I. S., and Hoekstra, D. J. (2002) On the mechanism of cationic amphiphile-mediated transfection. To fuse or not to fuse: is that the question? J. Membr. Biol. 189, 167-179.

(7) Barenholz, Y. (2001) Liposome application: problems and prospects. Curr. Opin. Colloid Interface Sci. 6, 66-77.

(8) Simberg, D., Danino, D., Talmon, Y., Minsky, A., Ferrari, E., Wheeler, C. J., and Barenholz, Y. (2001) Phase behavior, DNA ordering, and size instability of cationic lipoplexes. Relevance to optimal transfection activity. J. Biol. Chem. 276, 47453-47459.

(9) Radler, J. O., Koltover, I., Salditt, T., and Safinya, C. R. (1997) Structure of DNA-cationic liposome complexes: DNA intercalation in multilamellar membranes in distinct interhelical packing regimes. Science 275, 810-814.

(10) Astriab-Fisher, A., Fisher, M. H., Juliano, R., and Herdewijn, P. (2004) Increased uptake of antisense oligonucleotides by delivery as double stranded complexes. Biochem. Pharmacol. 68, 403-407.

(11) Astriab-Fisher, A., Sergueev, D. S., Fisher, M., Shax, B. R., and Juliano, R. L. (2000) Antisense inhibition of Pglycoprotein expression using peptide-oligonucleotide conjugates. Biochem. Pharmacol. 60, 83-90.

(12) Qabar, M. N., Urban, J., and Kahn, M. (1997) A facile solution and solid-phase synthesis of phosphotyrosine mimetic L-4-[diethylphosphono(difluoromethyl)]-phenylalanine ( $\mathrm{F}(2)-$ Pmp(Eto)(2)) derivatives. Tetrahedron 53, 11171-11178.

(13) Stetsenko, D. A., and Gait, M. (2001) A convenient solidphase method for synthesis of 3 '-conjugates of oligonucleotides. Bioconjugate Chem. 12, 576-586.

(14) Hovinen, J., Guzaev, A., Azhayev, A., and Lonnberg, H. (1994) Novel solid supports for the preparation of 3'-derivatized oligonucleotides: Introduction of 3 -alkylphosphate tether groups bearing amino, carboxy, carboxamido and mercapto functionalities. Tetrahedron 50, 7203-7218.

(15) Alahari, S. K., Dean, N. M., Fisher, M. H., Delong, R., Manoharan, M., Trivel, K. L., and Juliano, R. L. (1996) Inhibition of expression of the multidrug resistance-associated P-glycoprotein of by phosphorothioate and $5^{\prime}$ cholesterolconjugated phosphorothioate antisense oligonucleotides. Mol. Pharmacol. 50, 508-519.

(16) Alahari, S. K., Delong, R., Fisher, M. H., Dean, N. M., Viliet, P., and Juliano, R. L. (1998) Novel chemically modified oligonucleotides provide potent inhibition of P-glycoprotein expression. J. Pharmacol. Exp. Ther. 286, 419-428. 
(17) Wiethoff, C. M., Gill, M. L., Koe, J. G., and Middaugh, C. R. (2002) The structural organization of cationic lipid-DNA complexes. J. Biol. Chem. 277, 44980-44987.

(18) Zhang, Y., Garzon-Rodriguez, W., Manning, M. C., and Anchordoquy, T. J. (2003) The use of fluorescence resonance energy transfer to monitor dynamic changes of lipid-DNA interactions during lipoplex formation. Biochim. Biophys. Acta 1614, 182-192.

(19) Zelphati, O., and Szoka, F. C., Jr. (1996) Mechanism of oligonucleotide release from cationic liposomes. Proc. Natl. Acad. Sci. U.S.A. 93, 11493-11498.

(20) Madeira, C., Loura, L. M. S., Aires-Barros, M. R., Fedorov, A., and Prieto, M. (2003) Characterization of DNA/lipid complexes by fluorescence resonance energy transfer. Biophys. J. 85, 3106-3119.

(21) Vosch, T., Cotlet, M., Hofkens, J., Van Der Biest, K., Lor, M., Weston, K., Tinnefield, P., Sauer, M., Latterini, L.,
Müllen, K., and De Schrijver, F. C. (2003) Probing Förster type energy pathways in a first generation rigid dendrimer bearing two perylene imide chromophores. J. Phys. Chem. A 107, 6920-6931.

(22) Förster, V. T. (1949) Experimentelle und theoretische Untersuchung des zwischenmolekularen Übergangs von Elektronenanregungsenergie. Z. Naturforsch. 4A, 321-327.

(23) Ahn, K.-S., Ou, W., and Silver, J. (2004) Inhibition of certain strains of HIV-1 by cell surface polyanions in the form of cholesterol-labeled oligonucleotides. Virology 330, 50-61.

(24) Boutorine, A. S., and Kostina, E. V. (1993) Reversible covalent attachment of cholesterol to oligodeoxyribonucleotides for studies of the mechanisms of their penetration into eucaryotic cells. Biochemie 75, 35-41.

BC050022G 